\title{
Substituent Effect on the Association Phenomenon of an Aqueous Solution of Benzylidene Substituted Aniline at Different Temperatures
}

\author{
Mohammed A. Al-Iraqi Yaser O. Al-Allaf Kawther H. Al-Naimi \\ Department of Chemistry \\ College of Science \\ University of Mosul
}

E-mail: maaliraqi_54@yahoo.com

(Received 3/6/2012 ; Accepted 7/1/2013)

\begin{abstract}
Conductivity parameters of an aqueous solution of benzylidene substituted anilines (I-IV) have been determined at five different temperatures in the range of $283.15-318.15{ }^{\circ} \mathrm{K}$, through accurate conductance measurements. The obtained data were analyzed in accordance to Lee-Wheaton equation taking into account the activity of the electrolyte in the solution. The conductance measurement results were used to determine the association constants $\left(\mathrm{K}_{\mathrm{A}}\right)$ of ion-pairs, the mean distance between ions in solution, in addition to the molar conductance at infinite dilution $\left(\Lambda_{\mathrm{o}}\right)$ for the free ion in the solution. The dependence of $\left(\mathrm{K}_{\mathrm{A}}\right)$ values on the temperature has been examined by plotting $\log \mathrm{K}_{\mathrm{A}}$ against the reciprocal values of temperature $(1 / T)$, which showed linear relationship, where $\left(\mathrm{K}_{\mathrm{A}}\right)$ values decrease with increasing temperature. Moreover, the enthalpy $(\Delta \mathrm{H})$, Gibbs free energy $(\Delta \mathrm{G})$ and the entropy $(\Delta S)$ have been derived from this linear relationship.
\end{abstract}

Keywords: Ion-association, conductance, Schiff bases, benzylidene substituted aniline, Lee-Wheaton equation.

\section{درلسة تأثير المعوضلت علطلاهرة النجمع الأيوف المحالل المائية البنزبلين أنيلين

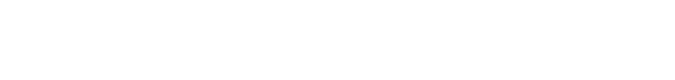

\section{الملغص}

مُ ققدير دول التوصيلية للمحالل المائية للبذزيلين أنيلين المعوض (I-IV) عند خهس درجلت حرارية

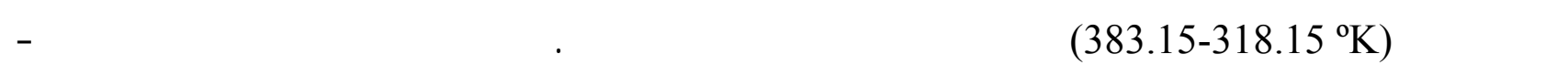

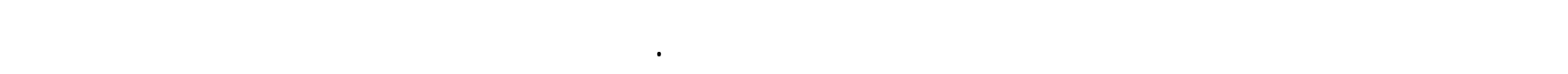

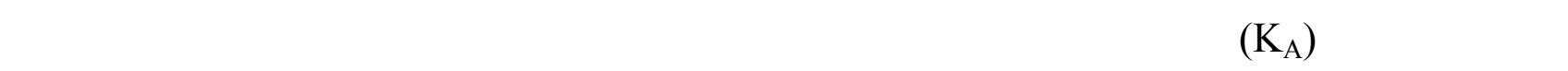

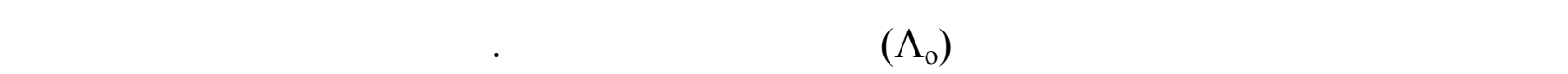




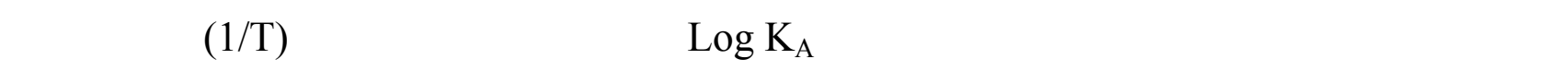 علاقة خطية، إذ انخفضت قيمة (KA ) بزيادة درجة الحرارة، فضلا عن ذلك هسبت قيم المحتوى الحراري

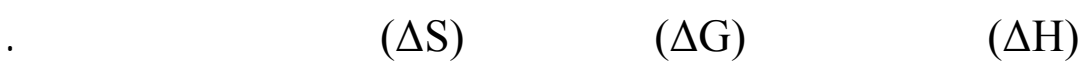

الكامل الدالة: التجمع الأيوفي، التوصيلية، قواعدشف، بنزيلين أنيلين، معادلة لي - ويتون.

\section{INTRODUCTION}

The effect of hydrogen bonding, relative permittivity and temperature on the transport properties and the association behavior was studied through the measurements of the specific conductance of sodium acetate, sodium propionate and sodium salicylate in $10 \%$, $20 \%$ and $30 \%(\mathrm{w} / \mathrm{w})$ methanol-water $\left(\mathrm{MeOH}-\mathrm{H}_{2} \mathrm{O}\right)$, ethanol-water $\left(\mathrm{EtOH}-\mathrm{H}_{2} \mathrm{O}\right)$ and glycerol-water $\left(\mathrm{GlyOH}-\mathrm{H}_{2} \mathrm{O}\right)$ mixtures at different temperatures $\left(293,298,303\right.$ and $\left.308{ }^{\circ} \mathrm{K}\right)$. The conductivity data have been analyzed using the Lee-Wheaton conductivity equation. The molar conductance $(\Lambda)$, limiting molar conductance $\left(\Lambda_{\mathrm{o}}\right)$, association constants $\left(\mathrm{K}_{\mathrm{A}}\right)$, Walden product $\left(\Lambda_{\mathrm{o}} \eta_{\mathrm{o}}\right)$, hydrodynamic radii $\left(\mathrm{R}_{\mathrm{H}}\right)$, fluidity ratio $(\mathrm{R})$, the activation energy of the transport process $\left(\mathrm{E}_{\mathrm{a}}\right)$ and standard thermodynamic parameters of association $\left(\Delta \mathrm{G}_{\mathrm{A}}, \Delta \mathrm{H}_{\mathrm{A}}\right.$ and $\left.\Delta \mathrm{S}_{\mathrm{A}}\right)$ were calculated and discussed (El-Dossoki, 2010). Considering the ionic nature of ionic liquids (ILs), ionic association is expected to be essential in solutions of ILs and have an important influence on their applications. Although numerous studies have been reported for the ionic association behavior of ILs in solution, quantitative results are quite scarce. Herein, the conductivities of ILs (1-butyl-3-methylimidazolium bromide) ([Cnmim] $[\mathrm{Br}])(\mathrm{n}=4,6,8,10,12)$, (1-n-butyl-3-methylimidazolium tetrafluoroborate) ([C4mim][BF4]) and (1-Butyl-3-methylimidazolium hexafluorophosphate) ([C4mim][PF6]) in various solvents (water, methanol, 1-propanol, 1-pentanol, acetonitrile, and acetone) were determined at $298.15{ }^{\circ} \mathrm{K}$ as a function of IL concentration. The conductance data were analyzed by the Lee-Wheaton (LW) conductivity equation in terms of the ionic association constant $\left(\mathrm{K}_{\mathrm{A}}\right)$ and the limiting molar conductance $\left(\Lambda_{\mathrm{o}}\right)$ (Wang et al., 2009).

The discovery of the electrical conductivity of material prepared from tetrathiofulavtene and tetracyanoquinodimethene (Frranis et al., 1973) initiated on intense searches for conductance materials which is still in progress. A number of other materials of similar type, with heterocyclic systems, have been found to play a major role in providing electron donor molecules.

The conductivity of the complexes of 8-hydroxyquinoline with some transition and alkaline earth metals in methanol were measured and Lee-Wheaton conductance equation was used to analyze the experimental data. It was found that this equation is very applicable for such type of complexes (Akrawi and Sarsem 2001). The electrical conductivity of aqueous solutions of o-benzene disulfonate, m-benzene disulfonate and 2,6-naphthalene disulfonate with $\left[\mathrm{Fe}(\mathrm{phen})_{3}\right]^{2+}$ was measured at a range of temperatures from $0{ }^{\circ} \mathrm{C}$ to $50^{\circ} \mathrm{C}$ to get a detailed thermodynamic information about the ion association and to examine the nature of the interactions in these solutions (Yokoyama et al., 1992). A clear understanding of the electronic structure and the spectral properties of benzylidene aniline was required for the explanation of their photochemical properties, phototropism and photoisomerism; in particular, one needs to determine the nature of their lower electronic excited states, e.g., the 
extent of charge-transfer character and the role of solvent, protonation and substitution, in altering the energies of these states (El-Bayoumi, 1971).

In this study, we have measured the conductivity of an aqueous solution of a series of benzylidene substituted aniline compounds at different temperatures in order to determine the mechanism of association from the thermodynamic point of view.

\section{Chemicals and apparatus}

\section{EXPERIMENTAL}

All chemicals were obtained from the usual commercial suppliers and used without further purification. Melting points were measured on electrothermal 9300 melting point apparatus and were uncorrected. The IR spectra (as $\mathrm{KBr}$ disc) were run with Shimadzu FT/IR spectrophotometer (computerized Bruker Tensor-27). UV-Visible spectra of the ethanolic solutions were measured at room temperature with Zeius PMQ II manual spectrophotometer using matched $10 \mathrm{~mm}$ fused silica cells. A thermostated water bath type Haake NK22, with a temperature deviation not greater than $\pm 0.1{ }^{\circ} \mathrm{C}$, is used. The conductance measurements were performed using Jenawy PCM3 conductivity meter.

\section{Preparation of benzylidene substituted anilines (I-IV):}

To a solution of substituted aniline $(0.005$ moles $)$ in $20 \mathrm{ml}$ absolute ethanol, $(0.005$ mole, $0.53 \mathrm{~g}$ ) of benzaldehyde was added. After refluxing for $5 \mathrm{hrs}$, the reaction mixture was allowed to cool. The resulting solid product was filtered off, dried and recrystallized several times from ethanol to give a pure product (Burgi, 1971). The physical and IR spectral data of the products are summarized in Table (1).

Table 1: The Physical properties of the Schiff bases (1-IV).

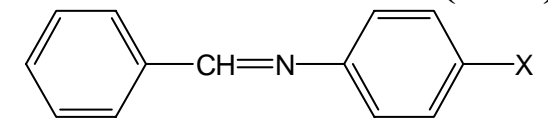

\begin{tabular}{|c|c|c|c|c|c|c|c|}
\hline \multirow{2}{*}{$\begin{array}{c}\text { Compd. } \\
\text { No. }\end{array}$} & \multirow[t]{2}{*}{ Colour } & \multirow[t]{2}{*}{$-\mathbf{X}$} & \multirow{2}{*}{$\begin{array}{c}\text { m.p. }{ }^{\circ} \mathrm{C} \\
\text { (Reported)* }\end{array}$} & \multirow{2}{*}{\begin{tabular}{|c|}
$\mathrm{U} . \mathrm{V}$. \\
$(\mathrm{EtOH})$ \\
$\lambda_{\max } \mathrm{nm}$
\end{tabular}} & \multicolumn{3}{|c|}{ I.R. (KBr disc), v $\left(\mathrm{cm}^{-1}\right)$} \\
\hline & & & & & $\mathbf{C}=\mathbf{N}$ & $\mathrm{C}=\mathrm{C}$ & $\mathrm{C}-\mathrm{X}$ \\
\hline I & Brown & $\mathrm{OH}$ & $\begin{array}{c}177-179 \\
(183)\end{array}$ & $\begin{array}{c}346 \\
294 \\
237 * *\end{array}$ & $1622(\mathrm{~s})$ & $\begin{array}{c}1580(\mathrm{~s}) \\
1502(\mathrm{~s}) \\
1480(\mathrm{w})\end{array}$ & $3350(b)$ \\
\hline II & $\begin{array}{l}\text { Faint } \\
\text { yellow }\end{array}$ & $\mathrm{COOH}$ & $\begin{array}{c}189-191 \\
(190-191)\end{array}$ & $\begin{array}{c}263 * * \\
214\end{array}$ & \begin{tabular}{|l|}
$1687(\mathrm{~s})$ \\
$3367(\mathrm{w})$ \\
\end{tabular} & $\begin{array}{l}1425(\mathrm{~s}) \\
1498(\mathrm{w})\end{array}$ & $\begin{array}{l}1317 \text { (s) sym C-O } \\
1595 \text { (s\&b) O-H }\end{array}$ \\
\hline III & $\begin{array}{c}\text { Yellowish } \\
\text { white }\end{array}$ & $\mathrm{Cl}$ & $\begin{array}{c}63-65 \\
(62-63)\end{array}$ & $\begin{array}{c}286 \\
241^{*}\end{array}$ & $1623(\mathrm{~s})$ & $\begin{array}{c}1581(\mathrm{~s}) \\
1483(\mathrm{~m}) \\
1448(\mathrm{~m})\end{array}$ & $756(\mathrm{~s})$ \\
\hline IV & Gray & $\mathrm{Br}$ & $\begin{array}{c}67-69 \\
(66)\end{array}$ & $\begin{array}{c}266 * * \\
272 \\
287 \\
\end{array}$ & $1620(\mathrm{~s})$ & $\begin{array}{c}1602(\mathrm{~s}) \\
1587(\mathrm{~s}) \\
1479(\mathrm{w})\end{array}$ & $819(\mathrm{~s})$ \\
\hline
\end{tabular}

* JACS, 75, 910, $1953 \quad * *$ for the $\lambda_{\max }$ 


\section{RESULTS AND DISCUSSION}

Correlation of the molecular structure and thermal study of the electrical conductivity of benzaldazine and its nitro derivatives were carried out. The values of activation energies obtained from the measurements, as well as, the energy gaps calculated from UV- visible spectra indicated that all compounds behave like a semiconducting material (El-Sayed et al., 1991). Therefore, a series of benzylidene anilines (I-IV) were prepared and used to estimate their conductivity. These Schiff bases were prepared from the reaction of benzaldehyde with substituted aniline. The structure of these compounds was assigned on the basis of their IR spectral data which are summarized in Table (1). The IR spectra show a characteristic absorption peaks at $1618-1631 \mathrm{~cm}^{-1}$ for $\mathrm{C}=\mathrm{N}$ bond stretching (Criddle and Eilis, 1976).

Conductivity measurement of aqueous solutions of benzylidene substituted anilines (I-IV) was carried out at five temperatures in the range of $283.15-315.15^{\circ} \mathrm{K}$. The values of the molar conductance $(\Lambda)$ of their solutions were given in Tables (2 A-E). The conductance data obtained were first analyzed in accordance with Lee-Wheaton equation. The correlations between the concentration of the aqueous solution of these Schiff bases and their equivalent conductance are shown in Figs. (1 A-E) which show a non-linear relationships. That means they are week electrolytes. The brief illustration of those figures was shown in figures $\left(1 \mathrm{~B}_{\mathrm{i} \text {-iv }}\right)$. The oppositely charged ions tend to form ion-pairs in the medium of low relative permittivity. At constant temperature, the concentration of free ions $(\mathrm{C} \alpha)$ and ion-pairs $[\mathrm{C}(1-\alpha)]$ are at equilibrium. This state was described by the thermodynamic equilibrium $(\mathrm{K})$ for the ion-association reaction. Since the ion pairs are nonconducting entities and the degree of their dissociation $(\alpha)$ can be given by the ratio between the molar conductivity of the electrolyte $(\Lambda)$ and the free ion $(\Lambda-C \alpha)$. Then the combination of the expressions for $\mathrm{K}$ and $\alpha$ can be given as:

$$
\Lambda=\frac{(\Lambda-\mathrm{C} \alpha)}{1+\mathrm{K}\left(\mathrm{C} / \mathrm{C}^{\circ}\right) \alpha \mathrm{y}^{2 \pm}}
$$

Where $\mathrm{C}^{\mathrm{o}}=1$ mole $\mathrm{dm}^{-3}, \mathrm{y}^{ \pm}$is the mean activity coefficient which can be obtained from equation 2:

$$
\mathrm{y}^{ \pm}=\exp \left(\frac{\mathrm{Kq}}{1+\mathrm{KR}}\right)
$$

which refers to the dissociated part of the electrolyte, $\mathrm{R}$ is the distance parameter which must be the least distance that two free ions can approach before they merge into an ionpair, or in other words, it is the furthest distance that separates two ions. The parameters $\mathrm{K}$ and $\mathrm{q}$ can be obtained from equation 3 and 4 respectively:

$$
\begin{aligned}
& \mathrm{K}^{2}=16000 \pi \mathrm{N}_{\mathrm{A}} \mathrm{qC} \alpha \\
& \mathrm{q}=\frac{\mathrm{e}^{2}}{8 \pi \varepsilon^{\circ} \varepsilon_{\mathrm{r}} \mathrm{KT}}
\end{aligned}
$$

If it is assumed that the dissociated part of the weak electrolyte acts like a completely hypothetical dissociated strong electrolyte of the same type, $\Lambda_{\mathrm{C} \alpha}$ can be replaced by any theoretical equation for conductivity in order to make a conductivity model, which was found by the Lee-Wheaton (Lee and Wheaton, 1978) equation (5):

$$
\begin{aligned}
\Lambda_{\mathrm{c} \alpha}= & \Lambda_{\mathrm{o}}\left[1+\mathrm{C}_{1}(\mathrm{KR})(\varepsilon \mathrm{K})+\mathrm{C}_{2}(\mathrm{KR})(\varepsilon \mathrm{K})^{2}+\mathrm{C}_{3}(\mathrm{KR})(\varepsilon \mathrm{K})^{3}\right]-(\rho \mathrm{K}) / \\
& (1+\mathrm{KR})\left[1+\mathrm{C}_{4}(\mathrm{KR})(\varepsilon \mathrm{K})+\mathrm{C}_{5}(\mathrm{KR})(\varepsilon \mathrm{K})^{2}+(\mathrm{KR}) / 12\right] \ldots \ldots \ldots
\end{aligned}
$$


Where the concentration dependent terms are both the plasma parameter ( $\varepsilon \mathrm{K})$ and $(\mathrm{KR})$, while the concentration coefficients $\varepsilon, \mathrm{K}$ and $\rho$ can be obtained from equations 6-8 respectively.

$$
\begin{aligned}
& \varepsilon=|\mathrm{Zi}|^{2} \mathrm{e}^{2} / \mathrm{DKT} \\
& \mathrm{K}^{2}=8 \pi \mathrm{Ne}^{2}|\mathrm{Zi}|^{2} \mathrm{C} / 1000 \mathrm{DKT} \\
& \rho=\mathrm{F} \zeta \mathrm{e}|\mathrm{Z}| / 3 \pi \eta
\end{aligned}
$$

Where $\mathrm{F}$ is the Faraday constant $\left(9.6486 \times 10^{4}\right), \zeta$ is the conversion factor (volt to e.s.u.) $=$ $1 / 299.7925$, and all other terms have previously been defined in details (Lee and Wheaton, 1978).

\begin{tabular}{|c|c|c|c|c|}
\hline $\begin{array}{r}\text { Conc. } \\
\times 10^{4}\end{array}$ & $\begin{array}{c}\stackrel{\Lambda}{\text { S. } \mathrm{mol}^{-1} \cdot \mathrm{cm}^{2}} \\
\text { p-COOH }\end{array}$ & $\begin{array}{c}\Lambda \\
\text { S. } \mathrm{mol}^{-1} \cdot \mathrm{cm}^{2} \\
\mathrm{p}-\mathrm{OH}\end{array}$ & $\underset{\mathrm{p}-\mathrm{Cl}}{\Lambda}$ & $\underset{\mathrm{p}-\mathrm{Br}}{\stackrel{\Lambda}{\text { S. }}} \mathrm{mol}^{-1} \cdot \mathrm{cm}^{2}$ \\
\hline 0.196 & 238.464 & 75.612 & \begin{tabular}{|l|}
52.346 \\
\end{tabular} & 36.239 \\
\hline 0.384 & 222.656 & 62.343 & 47.500 & 36.072 \\
\hline 0.565 & 203.427 & 62.438 & 48.339 & 36.026 \\
\hline 0.909 & 174.323 & 58.943 & 41.386 & 35.498 \\
\hline 1.228 & 156.889 & 57.557 & 38.061 & 35.365 \\
\hline 1.525 & 145.023 & 56.318 & 38.124 & 34.775 \\
\hline 1.803 & 136.572 & 54.376 & 36.672 & 34.348 \\
\hline 2.063 & 130.964 & 53.048 & 36.471 & 33.639 \\
\hline 2.307 & 123.537 & 52.379 & 36.072 & 33.353 \\
\hline 2.537 & 118.626 & 52.124 & 35.947 & 29.081 \\
\hline 2.753 & 115.118 & 52.175 & 35.612 & 28.197 \\
\hline 2.953 & 111.802 & 51.660 & 35.468 & 26.718 \\
\hline
\end{tabular}

Table 2-A: Molar conductance of aqueous solution of benzylidene substituted aniline as a function of concentration at $283.15^{\circ} \mathrm{K}$.

\begin{tabular}{|c|c|c|c|c|}
\hline $\begin{array}{c}\text { Conc. } \\
\times 10^{4}\end{array}$ & $\begin{array}{c}\stackrel{\Lambda}{\mathrm{S} . \mathrm{mol}^{-1} \cdot \mathrm{cm}^{2}} \\
\mathbf{p}-\mathrm{COOH}\end{array}$ & 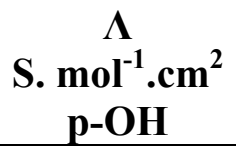 & 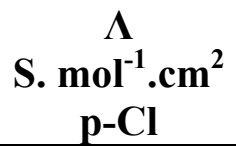 & $\underset{\mathrm{p}-\mathrm{Br}}{\stackrel{\Lambda}{\text { S. } \mathrm{mol}^{-1}} \cdot \mathrm{cm}^{2}}$ \\
\hline 0.196 & 209.387 & 56.406 & 22.746 & 35.197 \\
\hline 0.348 & 204.843 & 54.058 & 22.467 & 35.082 \\
\hline 0.565 & 195.371 & 51.582 & 22.361 & 34.599 \\
\hline 0.909 & 170.561 & 50.327 & 22.236 & 34.590 \\
\hline 1.228 & 154.104 & 50.285 & 22.103 & 34.260 \\
\hline 1.525 & 145.023 & 50.118 & 21.678 & 33.510 \\
\hline 1.803 & 137.836 & 50.105 & 21.497 & 34.386 \\
\hline 2.063 & 129.859 & 50.085 & 20.423 & 32.491 \\
\hline 2.307 & 125.513 & 50.075 & 20.066 & 31.353 \\
\hline 2.537 & 120.425 & 48.910 & 18.127 & 30.212 \\
\hline 2.753 & 117.602 & 48.339 & 17.812 & 26.718 \\
\hline 2.953 & 114.886 & 46.530 & 17.448 & 23.265 \\
\hline
\end{tabular}

Table 2-B: Molar conductance of aqueous solution of benzylidene substituted aniline as a function of concentration at $288.15{ }^{\circ} \mathrm{K}$. 
Table 2-C: Molar conductance of aqueous solution of benzylidene substituted aniline as a function of concentration at $298.15{ }^{\circ} \mathrm{K}$.

\begin{tabular}{|c|c|c|c|c|}
\hline $\begin{array}{c}\text { Conc. } \\
\times 10^{4}\end{array}$ & $\begin{array}{c}\stackrel{\Lambda}{\mathrm{S} . \mathrm{mol}^{-1} \cdot \mathrm{cm}^{2}} \\
\mathrm{p}-\mathrm{COOH}\end{array}$ & $\underset{\text { S-OH }}{\substack{\mathrm{mol}^{-1} \\
\text { p-Om }}}$ & 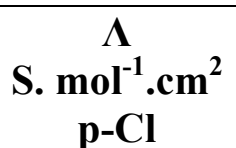 & $\underset{\mathrm{p}-\mathrm{Br}}{\stackrel{\Lambda}{\mathrm{mol}^{-1}} \cdot \mathrm{cm}^{2}}$ \\
\hline 0.196 & 331.530 & 69.795 & 34.897 & 29.081 \\
\hline 0.384 & 213.498 & 44.415 & 21.320 & 23.688 \\
\hline 0.569 & 195.428 & 46.325 & 21.288 & 20.224 \\
\hline 0.909 & 174.323 & 44.259 & 20.423 & 20.066 \\
\hline 1.228 & 159.674 & 43.574 & 19.013 & 18.566 \\
\hline 1.525 & 142.780 & 43.357 & 18.685 & 18.127 \\
\hline 1.803 & 133.411 & 43.081 & 18.330 & 17.360 \\
\hline 2.063 & 125.930 & 42.987 & 18.226 & 16.445 \\
\hline 2.307 & 118.544 & 42.723 & 17.780 & 15.542 \\
\hline 2.537 & 114.282 & 42.478 & 17.714 & 14.542 \\
\hline 2.753 & 112.305 & 42.132 & 17.400 & 14.132 \\
\hline 2.953 & 110.567 & 41.855 & 17.234 & 13.808 \\
\hline
\end{tabular}

Table 2-D: Molar conductance of aqueous solution of benzylidene substituted aniline as a function of concentration at $308.15{ }^{\circ} \mathrm{K}$.

\begin{tabular}{|c|c|c|c|c|}
\hline $\begin{array}{l}\text { Conc. } \\
\times 10^{4}\end{array}$ & \begin{tabular}{c}
\multicolumn{1}{|c}{${ }^{-1} \cdot \mathrm{mol}^{2}$} \\
p-COOH
\end{tabular} & $\begin{array}{c}\Lambda^{-1} \cdot \mathrm{cm}^{2} \\
\text { S. } \mathrm{mol}^{2} \\
\mathrm{p}-\mathrm{OH}\end{array}$ & $\begin{array}{c}\Lambda_{\text {S. } \mathrm{mol}^{-1} \cdot \mathrm{cm}^{2}} \\
\mathrm{p}-\mathrm{Cl}\end{array}$ & $\begin{array}{c}\Lambda \\
\substack{\text { S. } \mathrm{mol}^{-1} \cdot \mathrm{cm}^{2} \\
\mathrm{p}-\mathrm{Br}}\end{array}$ \\
\hline 0.196 & 187.031 & 52.175 & 30.071 & 34.813 \\
\hline 0.384 & 186.122 & 52.045 & 29.557 & 34.386 \\
\hline 0.569 & 167.173 & 51.675 & 29.400 & 34.348 \\
\hline 0.909 & 150.495 & 50.897 & 29.287 & 34.240 \\
\hline 1.228 & 135.537 & 50.285 & 29.084 & 34.143 \\
\hline 1.525 & 127.082 & 49.950 & 28.660 & 34.096 \\
\hline 1.803 & 118.868 & 49.337 & 27.850 & 33.955 \\
\hline 2.063 & 112.176 & 48.273 & 27.659 & 33.926 \\
\hline 2.307 & 107.230 & 45.148 & 23.826 & 33.861 \\
\hline 2.537 & 103.350 & 40.262 & 22.155 & 33.701 \\
\hline 2.753 & 101.038 & 35.625 & 17.812 & 35.625 \\
\hline 2.953 & 98.694 & 29.081 & 17.448 & 29.081 \\
\hline
\end{tabular}


Table 2-E: Molar conductance of aqueous solution of benzylidene substituted aniline as a function of concentration at $318.15{ }^{\circ} \mathrm{K}$

\begin{tabular}{|c|c|c|c|c|}
\hline $\begin{array}{l}\text { Conc. } \\
\times 10^{4}\end{array}$ & $\begin{array}{c}\Lambda_{\text {S. } \mathrm{mol}^{-1} \cdot \mathrm{cm}^{2}} \\
\text { p-COOH }\end{array}$ & 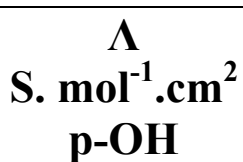 & $\underset{\substack{\Lambda \\
\text { S.Cl }}}{\mathrm{mol}^{-1} \cdot \mathrm{cm}^{2}}$ & 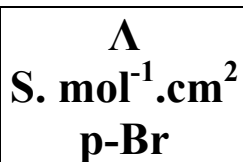 \\
\hline 0.196 & 187.031 & 54.820 & 40.714 & 33.540 \\
\hline 0.384 & 186.122 & 54.744 & 34.348 & 33.251 \\
\hline 0.569 & 165.159 & 54.666 & 34.260 & 33.155 \\
\hline 0.909 & 142.970 & 54.570 & 34.143 & 33.127 \\
\hline 1.228 & 136.465 & 53.862 & 34.096 & 33.107 \\
\hline 1.525 & 123.344 & 53.843 & 33.861 & 32.878 \\
\hline 1.803 & 120.133 & 53.743 & 33.639 & 31.563 \\
\hline 2.063 & 112.724 & 53.601 & 33.541 & 31.396 \\
\hline 2.307 & 109.206 & 52.367 & 33.251 & 30.099 \\
\hline 2.537 & 105.597 & 52.346 & 32.769 & 28.197 \\
\hline 2.753 & 101.867 & 50.468 & 32.656 & 23.750 \\
\hline 2.957 & 98.694 & 48.910 & 32.226 & 23.265 \\
\hline
\end{tabular}

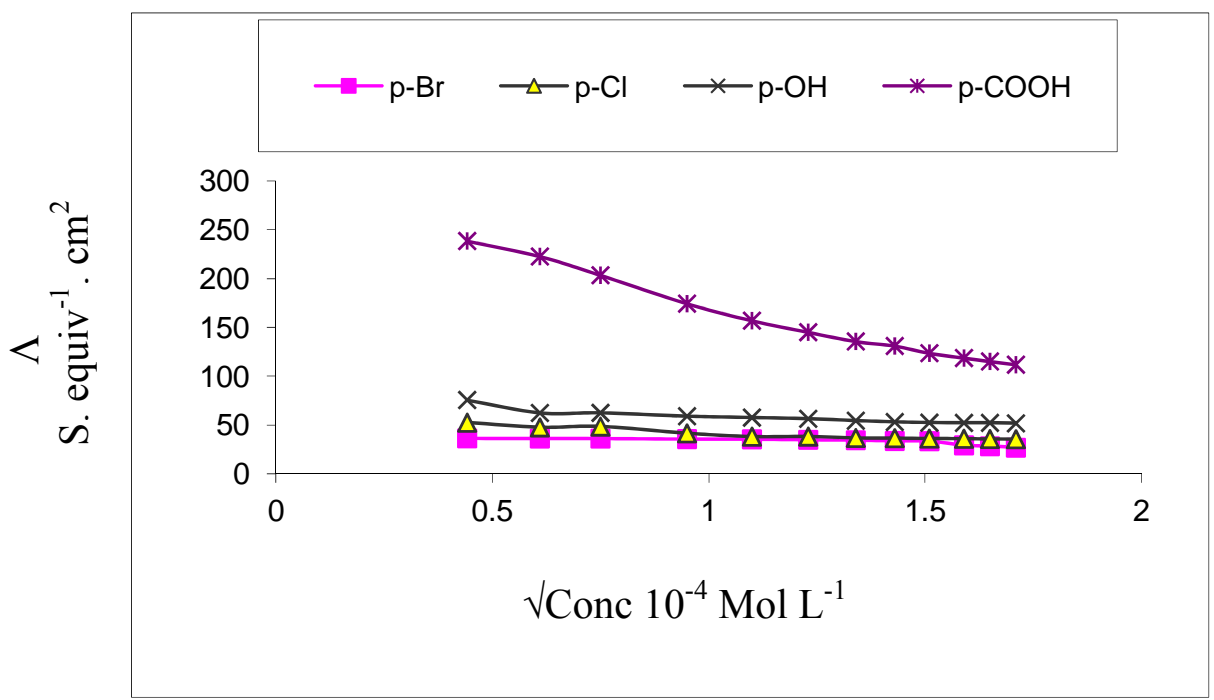

Fig. 1-A: Plot of $\Lambda$ against SQRt of concentration at $283.15^{\circ} \mathrm{K}$. 


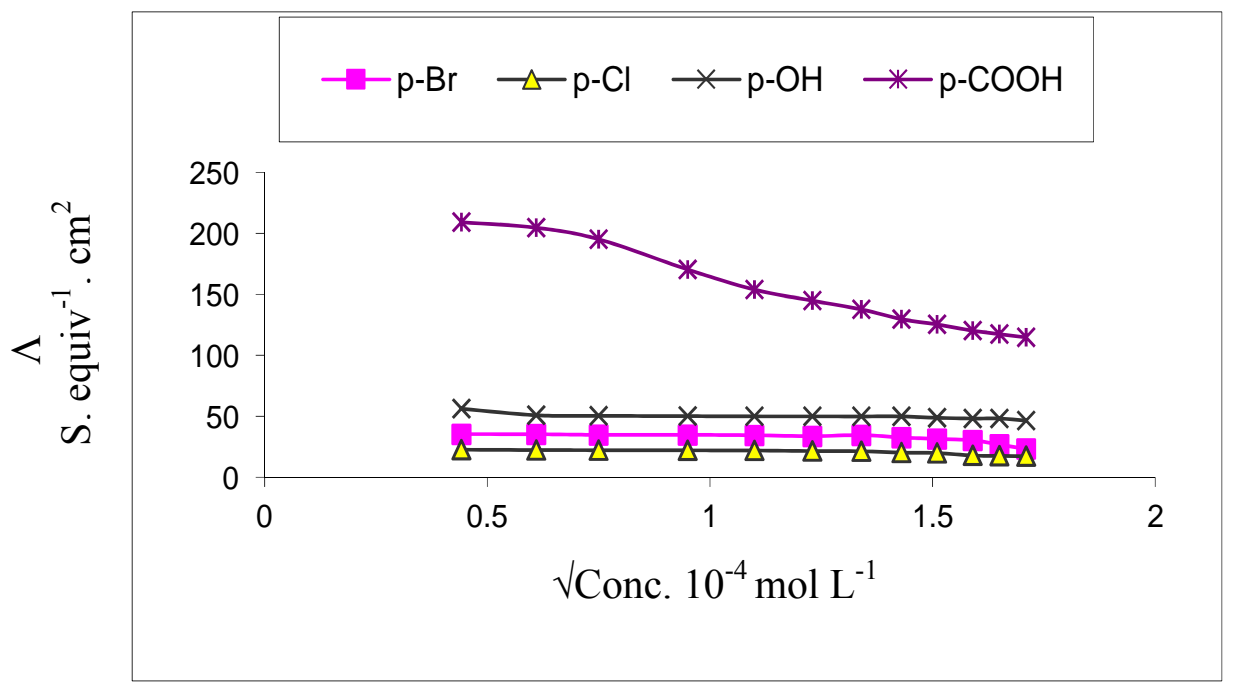

Fig. 1-B: Plot of $\Lambda$ against SQRt of concentration at $288.15^{\circ} \mathrm{K}$.
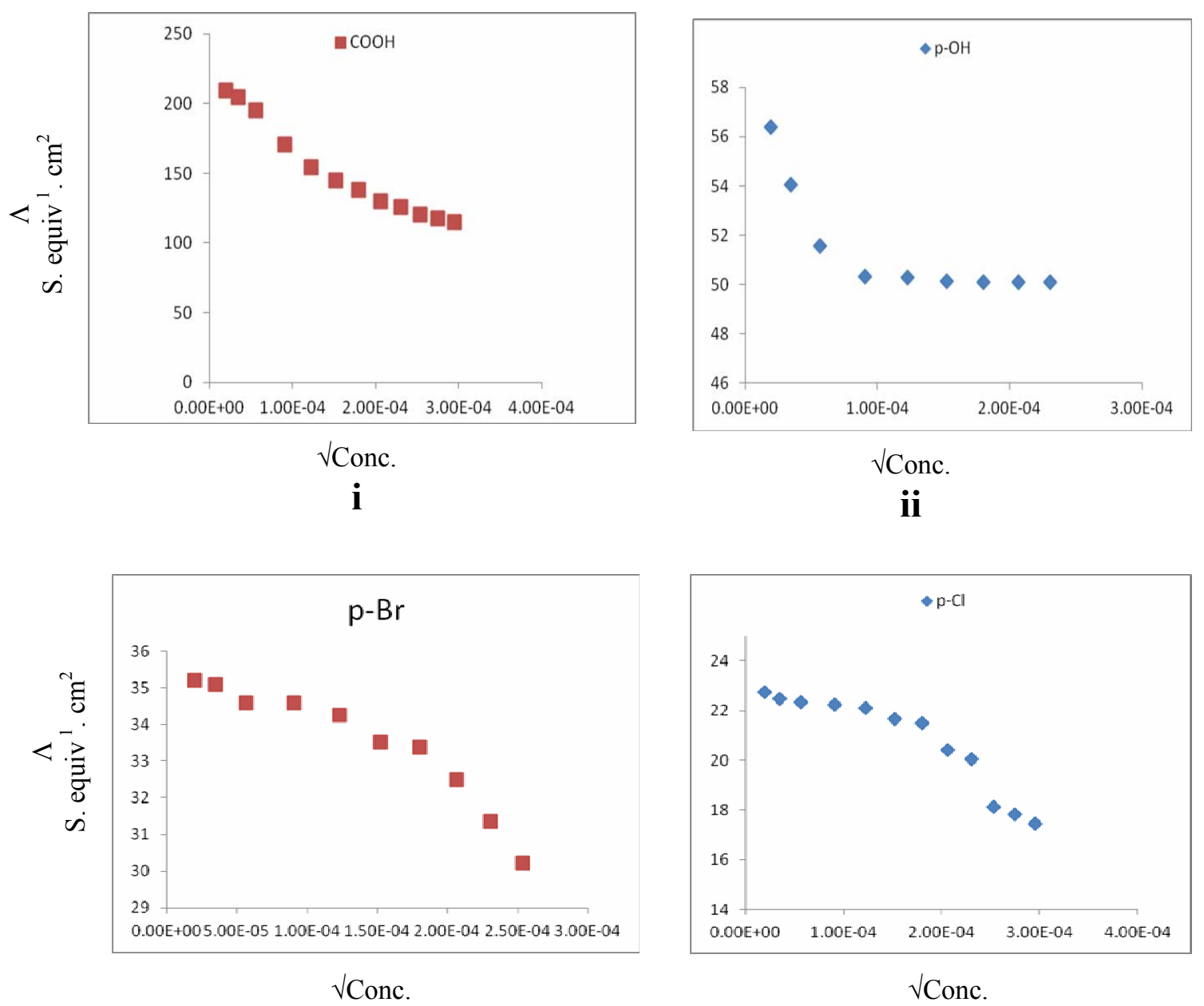

iii

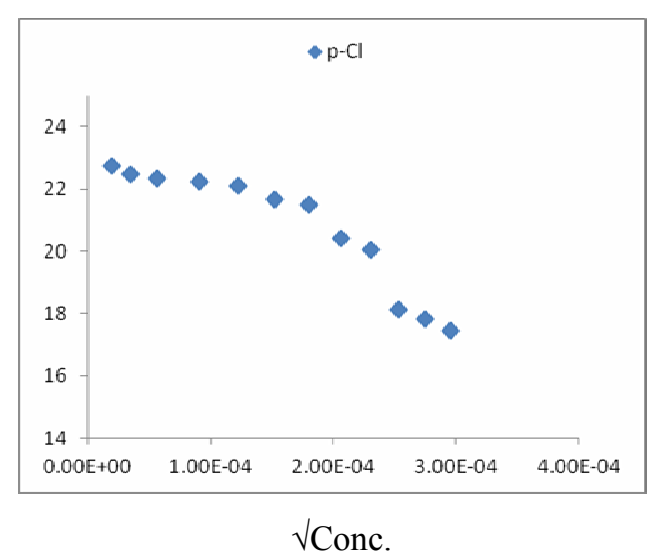

iv

Fig $1 B_{\text {i-iv }}$ : The illustration of figure 1-B. 


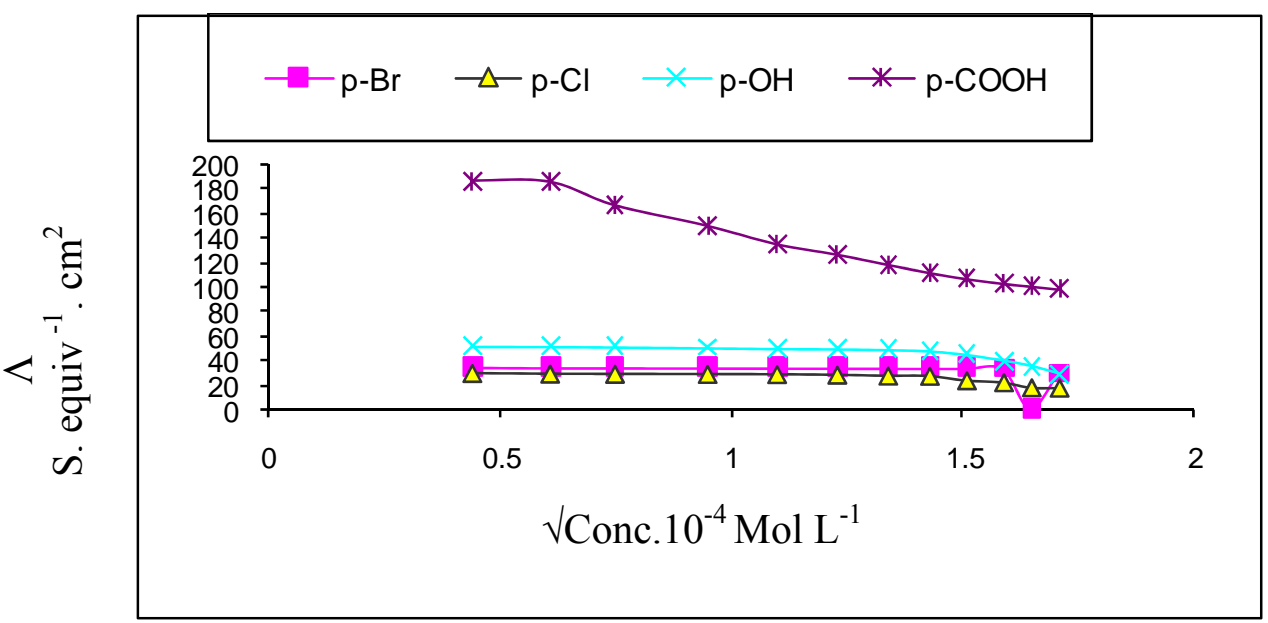

Fig. 1-C: Plot of $\Lambda$ against SQRt of concentration at $298.15{ }^{\circ} \mathrm{K}$.

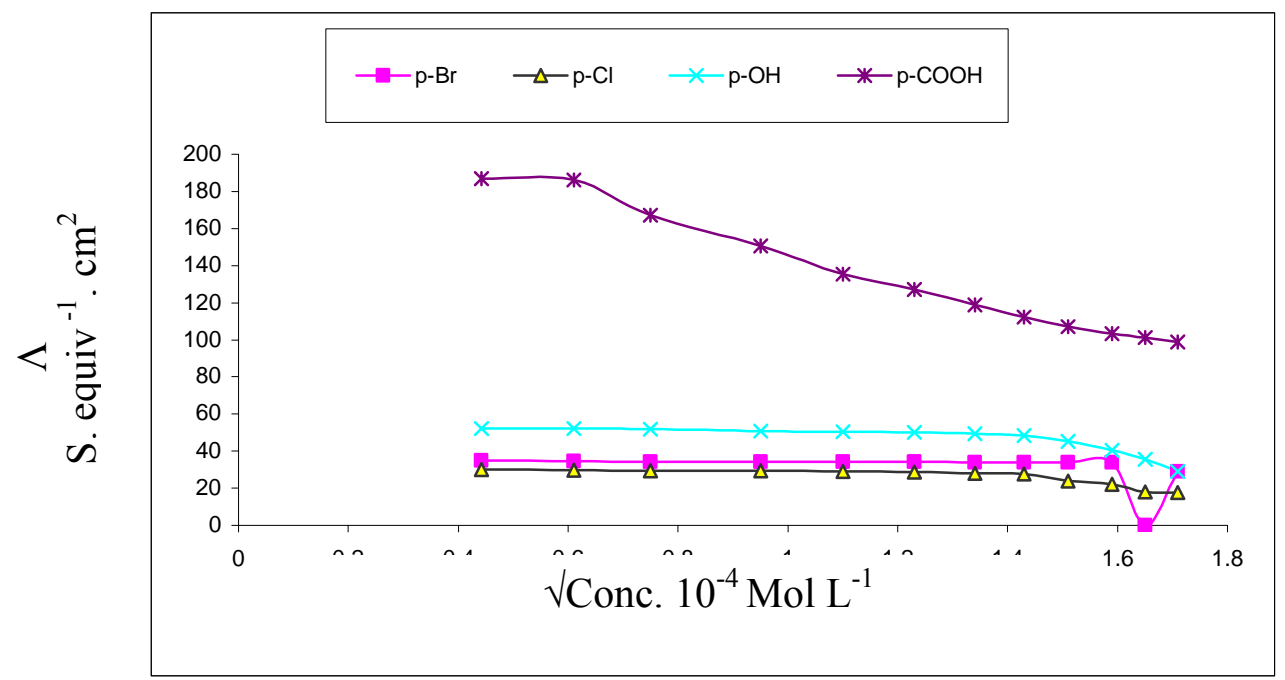

Fig. 1-D: Plot of $\Lambda$ against SQRt of concentration at $308.15^{\circ} \mathrm{K}$

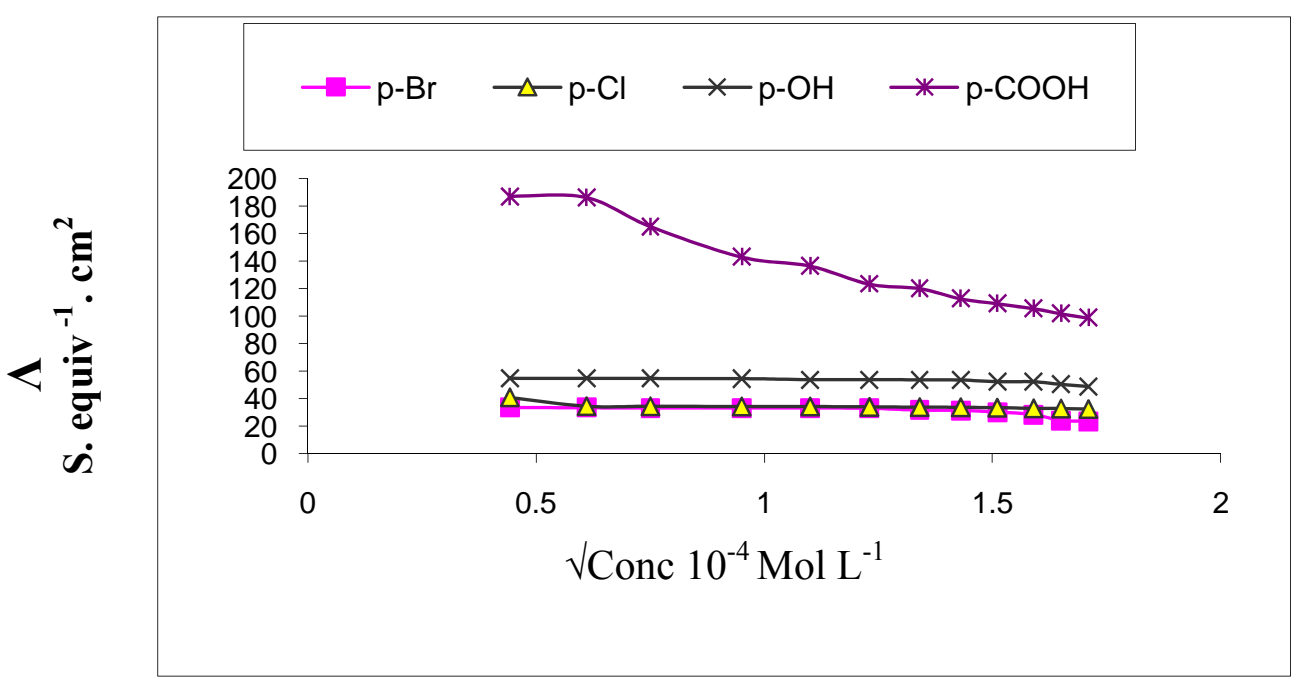

Fig. 1-E: Plot of $\Lambda$ against SQRt of concentration at $318.15^{\circ} \mathrm{K}$. 
The values of $\mathrm{K}_{\mathrm{A}}, \Lambda_{\mathrm{o}} \mathrm{R}$ of the aqueous solution of Schiff bases (I-IV) at 283.15-318.15 ${ }^{\circ} \mathrm{K}$ are shown in Table (3). Close inspection of this table shows that all values of $\mathrm{K}_{\mathrm{A}}$ were decreased with increasing temperatures, which were parallel to decrease of the values of the dielectric constant and viscosity with increasing temperature (Hikmat, 2002). This diversity of the values of $\mathrm{K}_{\mathrm{A}}$ may be attributed to the short range interaction and the H-bonding that are formed at low temperature [5].

On the other hand, the substituents on the anilino ring may play an important role and afford obvious differences in the $\mathrm{K}_{\mathrm{A}}$ values. The results, as represented in Table 3, show that the $\mathrm{K}_{\mathrm{A}}$ values decreased in the order of:

$$
\text { p- } \mathrm{OH}>\text { p- } \mathrm{COOH}>\mathrm{p}-\mathrm{Cl}>\mathrm{p}-\mathrm{Br}
$$

The difference in the $\mathrm{K}_{\mathrm{A}}$ values with respect to the above substituents are explicable in terms of their abilities to form hydrogen bonding and ion-solvent interaction, in addition to their electron withdrawing and electron donating abilities, since the increase in donor properties of the substituents will lead to the decrease of association and vice versa. The electron withdrawing ability of any group, results in delocalization of the electron density between the substituents and the rest of the molecule, and accordingly the polarizability of the molecule will be enhanced, giving rise the more association to take place.

Table 3: Fittest parameters on analysis of conductance data for aqueous solution of benzylidene substituted aniline at different temperatures.

\begin{tabular}{|c|c|c|c|c|c|c|c|c|}
\hline \multirow{2}{*}{$\begin{array}{c}\text { Temp } \\
\mathbf{K}\end{array}$} & \multicolumn{4}{|c|}{$\mathbf{p}-\mathbf{B r}$} & \multicolumn{4}{|c|}{$\mathbf{p}-\mathbf{C l}$} \\
\hline & $\mathbf{K}_{\mathbf{A}}$ & $\boldsymbol{\Lambda}_{\mathbf{0}}$ & $\mathbf{R A}^{\mathbf{0}}$ & $\boldsymbol{\sigma} \boldsymbol{\Lambda}$ & $\mathbf{K}_{\mathbf{A}}$ & $\boldsymbol{\Lambda}_{\mathbf{0}}$ & $\mathbf{R A}^{\mathbf{0}}$ & $\boldsymbol{\sigma \Lambda}$ \\
\hline 283 & 1452 & 38 & 10 & 0.014 & 3107 & 53 & 4.0 & 0.013 \\
\hline 288 & 1028 & 27 & 10 & 0.019 & 1020 & 24 & 3.0 & 0.01 \\
\hline 298 & 469 & 30 & 10 & 0.01 & 1042 & 41 & 14.0 & 0.052 \\
\hline 308 & 237 & 35 & 18 & 0.01 & 948 & 32 & 2.0 & 0.023 \\
\hline 318 & 108 & 36 & 20 & 0.018 & 520 & 37 & 3.0 & 0.011 \\
\hline
\end{tabular}

\begin{tabular}{|c|c|c|c|c|c|c|c|c|}
\hline \multirow{2}{*}{$\underset{{ }_{\mathbf{K}}}{\text { Temp }}$} & \multicolumn{4}{|c|}{ p-OH } & \multicolumn{4}{|c|}{ p-СОOH } \\
\hline & $\mathbf{K}_{\mathbf{A}}$ & $\Lambda_{0}$ & $\mathbf{R A}^{\mathbf{0}}$ & $\sigma \Lambda$ & $\mathbf{K}_{\mathbf{A}}$ & $\Lambda_{0}$ & $\mathbf{R A}^{\mathbf{0}}$ & $\sigma \Lambda$ \\
\hline 283 & 2810 & 71 & 10.0 & 0.022 & 15145 & 305 & 4.5 & 0.032 \\
\hline 288 & 3860 & 53 & 5.0 & 0.011 & 9752 & 250 & 20.0 & 0.039 \\
\hline 298 & 2842 & 60 & 6.0 & 0.04 & 5364 & 370 & 3.0 & 0.073 \\
\hline 308 & 1420 & 55 & 4.0 & 0.039 & 1981 & 228 & 10.0 & 0.040 \\
\hline 318 & 288 & 56 & 1.0 & 0.012 & 949 & 225 & 20.0 & 0.037 \\
\hline
\end{tabular}

The electronic effect of the substituents can be exhibited through inductive and resonance. The latter depends upon the co-planarity of the molecules. In fact, the 3Dstructures and the data obtained from the minimized geometry data, i.e., the charge, bond length, bond angle, interatomic distance and the twist angle (as a representative model Fig. 2 and Table 4 for compound I) for the Schiff bases (I-IV), show that these Schiff bases are not planar in which the two phenyl rings and the imino group are in different planes, i.e. the imino group is out the plane of each of the benzylidene and anilino phenyl rings as indicated 
by the selected twist angle for compound I as a representative model (Table 4) $\left(\mathrm{C}_{2} \mathrm{C}_{3} \mathrm{C}_{7} \mathrm{~N}_{9}=\right.$ -8.6, $\left.\mathrm{C}_{7} \mathrm{~N}_{9} \mathrm{C}_{10} \mathrm{C}_{11}=152.8, \mathrm{C}_{3} \mathrm{C}_{7} \mathrm{~N}_{9} \mathrm{C}_{10}=174.9, \mathrm{C}_{2} \mathrm{C}_{3} \mathrm{C}_{10} \mathrm{C}_{11}=-34.2\right)$. These values indicate that there are a series of steric congestions around $\mathrm{C}=\mathrm{N}$ group which is surrounded by the two phenyl rings, and the steric congestion exerted by anilino ring is more than that exerted by benzylidene ring, as a result of the valence shell electron-pair repulsion. Consequently, it can be concluded that the $\pi$ - frameworks consisting of the two phenyl rings and the $\mathrm{C}=\mathrm{N}$ group are not in the same plane. This means that the $\pi$ - clouds of the two phenyl rings and the $\mathrm{C}=\mathrm{N}$ group are extensively not delocalized, i.e. the substituents can not affect the whole system through the resonance, but they can affect only the anilino ring because these groups are in the same plane of this ring as it is indicated by the bond angle $\mathrm{O}_{16} \mathrm{C}_{13} \mathrm{C}_{12}=0.0$ (Fig. 2).

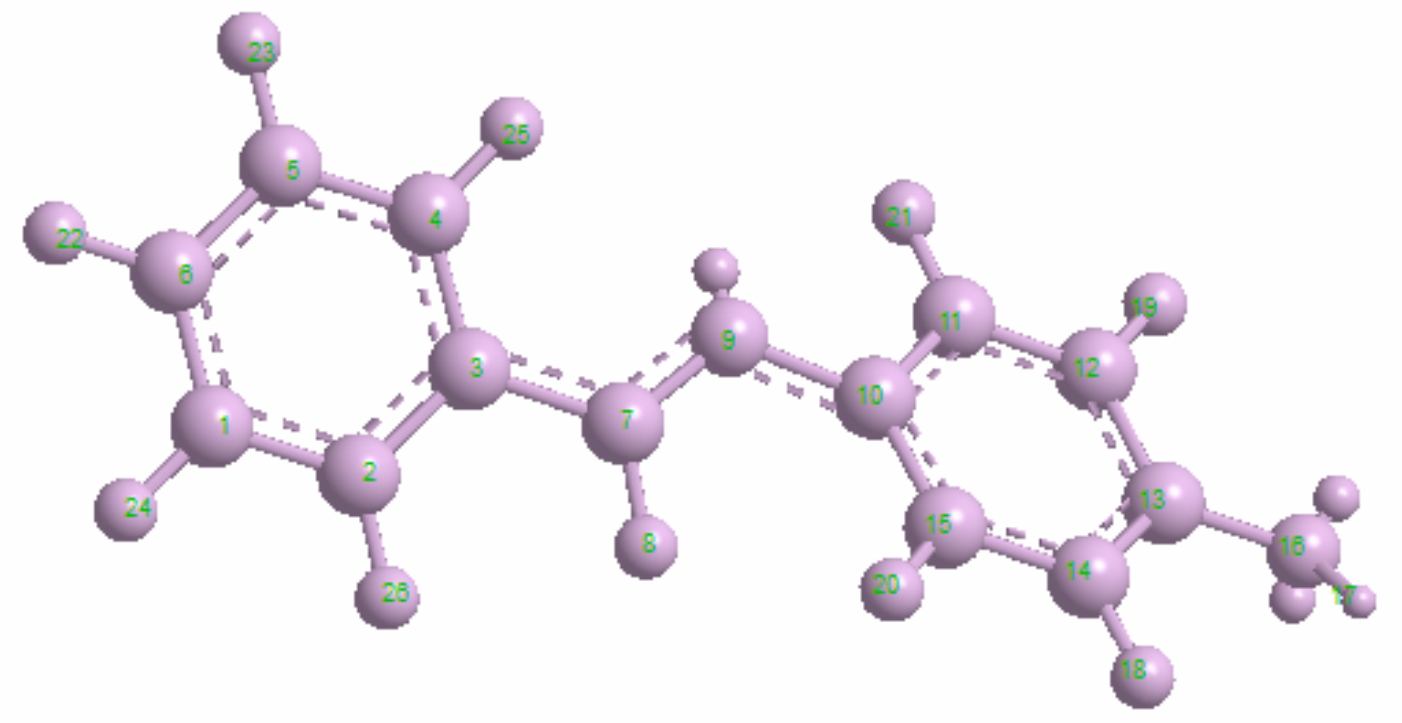

Fig. 2: The 3-D structure of benzylidene p-hydroxyaniline.

Table 4: Twist angles and dipole of benzylidene substituted aniline.

\begin{tabular}{|c|c|c|c|c|c|c|c|}
\hline Compd. & & \multicolumn{4}{|c|}{ Twist angle } & Bond angle & \\
\cline { 3 - 8 } No. & $\mathbf{X}$ & $\mathbf{C}_{\mathbf{2}} \mathbf{C}_{\mathbf{3}} \mathbf{C}_{\mathbf{7}} \mathbf{N}_{\mathbf{9}}$ & $\mathbf{C}_{\mathbf{7}} \mathbf{N}_{\mathbf{9}} \mathbf{C}_{\mathbf{1 0}} \mathbf{C}_{\mathbf{1 1}}$ & $\mathbf{C}_{\mathbf{3}} \mathbf{C}_{\mathbf{7}} \mathbf{N}_{\mathbf{9}} \mathbf{C}_{\mathbf{1 0}}$ & $\mathbf{C}_{\mathbf{2}} \mathbf{C}_{\mathbf{3}} \mathbf{C}_{\mathbf{1 0}} \mathbf{C}_{\mathbf{1 1}}$ & $\mathbf{X}_{\mathbf{1 3}} \mathbf{C}_{\mathbf{1 2}}$ & Dipole \\
\hline I & $\mathrm{OH}$ & -8.6 & 152.8 & 174.9 & -34.2 & 0.0 & 0.817 \\
\hline $\mathrm{II}$ & $\mathrm{COOH}$ & 172.6 & -37.4 & 178.7 & -41.9 & 0.0 & 3.175 \\
\hline $\mathrm{III}$ & $\mathrm{Br}$ & 172.4 & -123.3 & 31.0 & 179.2 & 0.0 & 3.088 \\
\hline $\mathrm{IV}$ & $\mathrm{Cl}$ & -6.9 & -24.5 & 177.8 & 150.9 & 0.0 & 2.243 \\
\hline
\end{tabular}

The other factor exhibited by the substituents is the inductive effect, which leads to increase the polarizability of the molecules. The dipole of the molecules (I-IV) (Table 4) obtained from the minimized geometry calculation with respect to the substituents was decreased in the following sequence:

$$
\mathrm{COOH}>\mathrm{Br}>\mathrm{Cl}>\mathrm{OH}
$$

This sequence was in a good agreement with the order of the substituent constants ( $\sigma_{\mathrm{m}}$ values) of these substituents that attributed to the inductive effect, but this sequence does not coincide with the order $\mathrm{K}_{\mathrm{A}}$ values. On the light of these results, it appeared that $\mathrm{K}_{\mathrm{A}}$ values did not depend only on the electronic effect of the substituents, but on other factors, such as hydrogen bonding, which play an important role in the determination of $\mathrm{K}_{\mathrm{A}}$ values. 
The $\mathrm{OH}$ group has an inductive effect as electron withdrawing, but it is suitable to form strong hydrogen bonding, while $\mathrm{Br}$ and $\mathrm{Cl}$ groups have a higher inductive effect, as electron withdrawing than $\mathrm{OH}$ group but they cannot form hydrogen bonding, and accordingly, compound II has a higher $\mathrm{K}_{\mathrm{A}}$ value than that of compound III and IV.

Moreover, the carboxy group was expected to exert larger $\mathrm{K}_{\mathrm{A}}$ value, but the results showed the contrast. This observation can be explicable in terms of formation of dimers of benzylidene p-carboxyaniline (Burgi and Dunitz, 1971) which results in packing arrangement completely different from that of other substituted anilino compounds and therefore, compound II has a lower $\mathrm{K}_{\mathrm{A}}$ value than compound III.

The values of $\Lambda_{0}$, as shown in Table (3), are decreased with increasing temperature. This change is expected, since the forces between ions are decreased, and hence the mobility of ions increased in accordance with increasing the dielectric constants of the medium (Al-Sattar, 2002).

The values of distance parameter $(\mathrm{R})$ are almost more than $3 \mathrm{~A}^{\circ}$ (according to Bjerrums physical concept of ionic association), which means that the electrolytes form solvent separated ion pairs in water. Furthermore, it can be noted from Table (3), that $\left(\sigma_{\Lambda}\right)$ possesses small values which give an indication about the fittest values.

The temperature dependence of the association of the Schiff bases solutions is the most important key toward association description. It has been suggested that the conductance is proportional to the strength of association between Schiff base and the solvent (El-Sayed et al., 1991). Hence, according to Arrhenius equation, the molecule must have acquired certain critical enthalpy $\Delta \mathrm{H}^{\circ}$. This enthalpy can be obtained simply by plotting $\log \mathrm{K}_{\mathrm{A}}$ against the reciprocal of the absolute temperatures. The linearity of the slope provides strong evidence for the consistence of the conductivity with Arrhenius equation. The plot of $\log \mathrm{K}_{\mathrm{A}}$, using the data listed in Table (5), versus $1 / \mathrm{T}$ over a range of $35^{\circ}$ was carried out, and gave excellent straight lines (Fig. 3).

The thermodynamic parameters $\Delta \mathrm{H}^{0}, \Delta \mathrm{G}^{0}$ and $\Delta \mathrm{S}^{0}$ are determined as follows:

The standard enthalpy of ion association reaction $\left(\Delta \mathrm{H}^{\circ}\right)$ of the charge transport was evaluated by the least-square treatment of the above data. The standard deviation of each enthalpy was derived from the standard deviation of the corresponding slope. The standard Gibbes free energy $\left(\Delta G^{0}\right)$ was determined from the values of $K_{A}\left(\Delta G^{0}=-R T \ln K_{A}\right)$, while the entropy of ion-pair formation was determined from the linear combination of the two previous variables (Tominic et al., 2004) as follows:

$$
\Delta \mathrm{S}=(\Delta \mathrm{H}-\Delta \mathrm{G}) / \mathrm{T}
$$

The thermodynamic results obtained are tabulated in Table (6).

It can be noted from Table (6) that the values of $\Delta \mathrm{H}^{\circ}$ of the ion association in water are negative, i.e., the process is exothermic and the evolution of heat was attributed to the ionsolvent interaction, in addition to the short-range interactions such as hydrogen-bond formation.

The order of $\left(-\Delta \mathrm{H}^{0}\right)$ corresponding to the Schiff bases (I-IV), related to the substituents is decreased in the following sequence:

$$
\text { p- } \mathrm{OH}>\mathrm{p}-\mathrm{COOH}>\mathrm{p}-\mathrm{Br}>\mathrm{p}-\mathrm{Cl}
$$

Compound I has higher $\left(-\Delta \mathrm{H}^{0}\right)$ value than that of other compounds despite its $\mathrm{K}_{\mathrm{A}}$ value is lower than that of compound II. This observation is easily accounted in the terms of hydrogen bond formation, in which the association between $\mathrm{OH}$ and water is more than that 
between $\mathrm{COOH}$ and water, as it is mentioned previously that the $\mathrm{COOH}$ compound present in a dimmer form through intermolecular hydrogen bonding, and hence the intermolecular hydrogen bonding with water was reduced and accordingly $\left(-\Delta \mathrm{H}^{\circ}\right)$ become smaller. The $\mathrm{p}-\mathrm{Br}$ and $\mathrm{p}-\mathrm{Cl}$ compounds have low interaction with the solvent due to the absence of $\mathrm{H}$ bonding, so they have low $\left(-\Delta H^{\circ}\right)$ values. On the other hand, the $\Delta S^{o}$ values of the interaction of the Schiff bases (I-IV) with water represented by their groups are decreased in the following order: $\mathrm{p}-\mathrm{OH}>\mathrm{p}-\mathrm{Br}>\mathrm{p}-\mathrm{COOH}>\mathrm{p}-\mathrm{Cl}$

Table 5: The calculated values of $\log K_{A}$ vs 1/T.

\begin{tabular}{|c|c|c|c|c|}
\hline $1 / \mathbf{T}$ & $\begin{array}{c}\log \mathbf{K}_{\mathbf{A}} \\
\mathbf{p - B r}\end{array}$ & $\begin{array}{c}\operatorname{Log~K}_{\mathbf{A}} \\
\mathbf{p - O H}\end{array}$ & $\begin{array}{c}\text { Log K } \\
\mathbf{p}-\mathbf{C O O H}\end{array}$ & $\begin{array}{c}\log \mathbf{K}_{\mathbf{A}} \\
\mathbf{p - C l}\end{array}$ \\
\hline 0.00353 & 7.260 & 9.990 & 9.625 & 8.041 \\
\hline 0.00347 & 6.935 & 8.258 & 9.185 & 7.390 \\
\hline 0.00335 & 6.150 & 7.952 & 8.531 & 6.948 \\
\hline 0.00324 & 5.465 & 7.258 & 7.591 & 6.854 \\
\hline 0.00314 & 4.682 & 5.662 & 6.822 & 6.822 \\
\hline
\end{tabular}

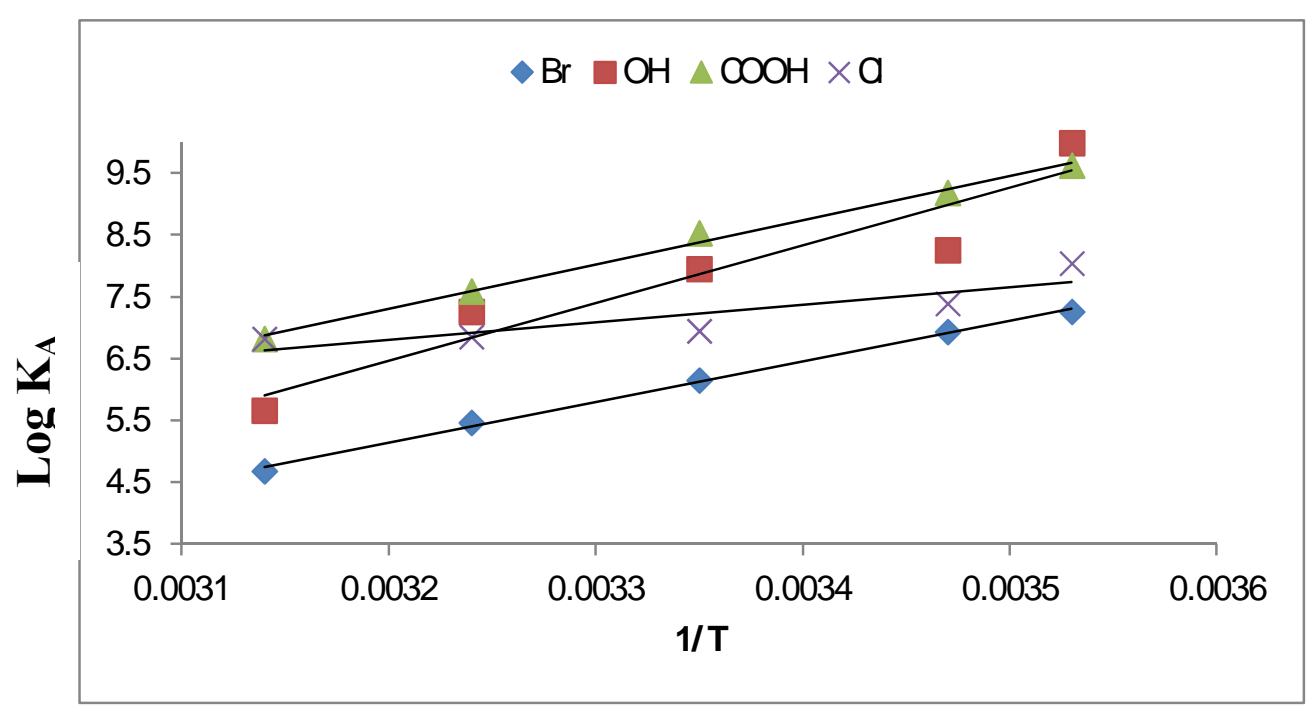

Fig. 3: Plot of $\log K_{A}$ against 1/T for benzylidene substituted aniline in water at different temperatures.

The positive values of $\Delta S^{o}$ for all compounds indicate the higher degree of freedom as a result of decrease in the orientation of the solvent molecules when the ion pair was formed in addition to the salvation of the solute molecules (Kubota et al., 1988), i.e. the molecules were spread in the solvent.

The $\Delta \mathrm{G}^{\mathrm{o}}$ values for conductivity are negative which indicates that the thermodynamic parameter $\Delta \mathrm{G}^{\mathrm{o}}$ for the conductance process of Schiff base salvation have -ve values, hence this process takes place spontaneously due to the interactions as it is suggested above. 
Table 6: The thermodynamic parameters calculated from the ion association constants of substituted benzylidene aniline in water at different temperatures.

\begin{tabular}{|c|c|c|c|c|c|c|}
\hline \multicolumn{4}{|c|}{ p-Br } & \multicolumn{3}{|c|}{ p-Cl } \\
\hline $\begin{array}{l}\text { Temp } \\
{ }^{0} \mathbf{K}\end{array}$ & $\begin{array}{c}-\Delta \mathbf{H} \\
\mathrm{KJ} / \mathrm{mol}\end{array}$ & $\begin{array}{c}-\Delta G \\
K J / m o l e\end{array}$ & $\begin{array}{c}\Delta \mathrm{S} \\
\mathrm{J} / \mathrm{mol} \text {.deg. }\end{array}$ & \begin{tabular}{c|}
$-\Delta \mathbf{H}$ \\
$\mathrm{KJ} / \mathrm{mol}$
\end{tabular} & $\begin{array}{c}-\Delta \mathbf{G} \\
\mathbf{K J} / \mathbf{m o l}\end{array}$ & $\begin{array}{c}\Delta S \\
\mathrm{KJ} / \mathrm{mol}\end{array}$ \\
\hline 283.16 & 6.666 & 4.122 & 8.984 & 4.324 & 4.553 & 0.808 \\
\hline 288.15 & & 4.025 & 9.165 & & 4.159 & 0.225 \\
\hline 298.15 & & 3.667 & 10.058 & & 4.148 & 0.607 \\
\hline 308.15 & & 3.368 & 10.702 & & 4.224 & 0.324 \\
\hline 318.15 & & 2.970 & 11.588 & & 3.978 & 1.087 \\
\hline \multicolumn{4}{|c|}{ p-OH } & \multicolumn{3}{|c|}{ p-COOH } \\
\hline $\begin{array}{c}\text { Temp } \\
{ }^{0} \mathbf{K}\end{array}$ & $\begin{array}{c}-\Delta \mathrm{H} \\
\mathrm{KJ} / \mathrm{mol}\end{array}$ & $\begin{array}{c}-\Delta G \\
\text { KJ/mole }\end{array}$ & $\begin{array}{c}\Delta S \\
\text { J/mol.deg. }\end{array}$ & \begin{tabular}{|c|}
$-\Delta \mathrm{H}$ \\
$\mathrm{KJ} / \mathrm{mol}$
\end{tabular} & $\begin{array}{c}-\Delta \mathrm{G} \\
\mathrm{KJ} / \mathrm{mol}\end{array}$ & $\begin{array}{c}\Delta \mathrm{S} \\
\mathrm{KJ} / \mathrm{mol}\end{array}$ \\
\hline 283.16 & 11.025 & 5.657 & 16.975 & 7.272 & 5.450 & 6.434 \\
\hline 288.15 & & 4.765 & 21.755 & & 5.293 & 6.867 \\
\hline 298.15 & & 4.740 & 21.075 & & 5.087 & 7.328 \\
\hline 308.15 & & 4.473 & 21.261 & & 4.678 & 8.417 \\
\hline 318.15 & & 3.662 & 23.142 & & 4.340 & 9.215 \\
\hline
\end{tabular}

\section{REFERENCES}

Akrawi, B.A.; Sarsem, L.A. (2001). The electrolytic conductivity of oxime with transition alkaline earth chloride complexes in methanol at $25{ }^{\circ}$ C. Raf. J. Sci. 12 (2), 17-27.

Al-Sattar, A.A. (2002). The electrical conductivity study of 2,5-di(2,4-dichlorophenoxy methyl)-1,3,4-oxadiazole in methanol-water mixtures at $25^{\circ} \mathrm{C}$. Raf. J. Sci. 12 (3), 9.

Burgi, H.B.; Dunitz, J.D. (1971). Molecular conformation of benzylidene anilines. Helvetica Chem. Acta, 5415, 1255.

Criddle, W.J.; Eilis, G.P. (1976). "Spectral and Chemical Characterization of organic compounds". John Wiley and Sons, Inc., London.

El-Bayoumi, M.A.; El-Aasser, M.; Abdel-Halim, F. (1971). Electronic spectra and structure of Schiff bases. I. Benzanils. J. Amer. Chem. Soc. 93 (1-3), 586-590.

El-Dossoki, F.I. (2010). Effect of hydrogen bond, relative permittivity and temperature on the transport properties and the association behavior of some 1:1 electrolytes in some binary mixed solvents. J. molecular Liquid, 151(1), 1.

El-Sayed, B.A.; Shaaban, S.M.; El-Desoky, M.M.; Ahmed, M.A. (1991). The electrical conductivity of some azine compounds. J. Material Sci. 2(1), 11-13.

Frranis, J.; Cowan, D.O.; Walatka, V.Jr.; Peristsm, J.H. (1973). The electrical conductivity of some fulavlene compounds. J. Amer. Chem. Soc. 95, 984.

Hikmat, N.A. (2002). Association in tetraethyl ammonium bromide solution in sodium carboxymethyl cellulose-water mixture. Iraqi J. Chem, 28 (1), 107-116.

Jones, G.; Bradshaw, B.C. (1933). The measurement of conductance of electrolytes. J. Amer. Chem. Soc. 55, 1780. 
Kubota, E.; Mochizuki, Y.; Yokoi, M. (1988). Conductivity of Iron (II) sulfate in aqueous solution at various temperatures. Bull. Chem. Soc. Jp. 61(10), 3723.

Lee, W.H.; Wheaton, R.J. (1978). Conductance of symmetrical, unsymmetrical and mixed electrolytes. J. Chem. Soc. Faraday Trans. II, 740.

Tominic, I.; Tomas, R.; Visic, M.M.; Sokol, V. (2004). Conductometric study of hydrobromic acid in 2-propanol-water mixtures. Croatica Chem. Acta. 77(3), 537.

Wang, H.; Wang, J.; Zhang, S.; Pei, Y.; Zhuo, K. (2009). Ionic association of the ionic liquids [C4mim][BF4], [C4mim][PF6] and [Cnmim]Br in molecular solvents. Eur. J. Chemphyschem, 10(14), 2516-2523.

Yokoyama, H.; Ohta, T.; Iida, M. (1992). Conductomotric study of ion association between Tris (ethylenediamine cobalt III) and monovalent anions at temperatures from zero to $50{ }^{\circ}$ C. Bull. Chem. Soc. Jp. 65, 2901. 